\title{
Combined Approaches to Xylose Production from Corn Stover by Dilute Acid Hydrolysis
}

A. Fehér, C. Fehér, M. Rozbach, and Z. Barta*

Department of Applied Biotechnology and Food Science, Faculty of Chemical Technology and Biotechnology, Budapest University of Technology and Economics, Budapest, Hungary, Müegyetem rkp. 3. Budapest H-1111, Hungary

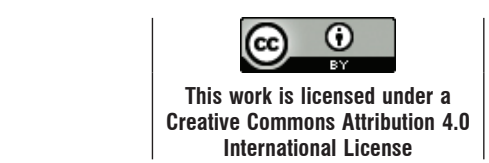 \\ doi: 10.15255/CABEQ.2016.913 \\ Original scientific paper \\ Received: June 3, 2016 \\ Accepted: March 14, 2017
}

\begin{abstract}
Corn stover is a lignocellulosic biomass, an agricultural by-product, a possible raw material for xylose production. In this study corn stover was hydrolyzed with sulfuric and hydrochloric acid. In the presented work, hydrochloric acid resulted in the highest, $88.8 \%$ xylose yield of theoretical under the conditions of $2 \%(\mathrm{w} / \mathrm{w})$ hydrochloric acid concentration, 40-minute reaction time, $10 \%(\mathrm{w} / \mathrm{w})$ dry matter, at $120{ }^{\circ} \mathrm{C}$. Sulfuric acid experiments resulted in $81.9 \%$ xylose yield of theoretical by using $1.5 \%(\mathrm{w} / \mathrm{w})$ sulfuric acid, 60-minute reaction time, at $140{ }^{\circ} \mathrm{C}, 7 \%$ (w/w) dry matter. Acid hydrolysis at low dry matter content resulted in relatively low sugar concentrations. Hydrolyzate recycling concentrated xylose to three-times, while the recycling does not decrease the xylose yields. It is also shown that the pseudo first-order and biphasic kinetic models can be based on total sugar concentrations.
\end{abstract}

Key words:

pretreatment, xylose, hydrolyzate recycling, kinetic modelling

\section{Introduction}

Recently, more attention has been paid to increasing utilization of lignocellulosic biomass. Lignocellulosic biomass is an abundant, renewable, low-cost feedstock having the potential to be converted into value-added bioproducts. Lignocellulosic biomass in general consists of mainly three different types of polymers: $38-50 \%$ cellulose, 23-32\% hemicellulose, and 15-25\% lignin on dry basis. ${ }^{1-3}$ To effectively convert lignocellulosic materials into valuable products pretreatment is inevitable. ${ }^{4}$

Acid pretreatment of lignocellulosic feedstock at relatively high temperatures helps to remove part of the lignin from the structure, and solubilizes cellulose and hemicellulose to various extents. ${ }^{1}$ Two categories of acid treatments can be distinguished: concentrated acid/low temperature and dilute acid/ high temperature. For industrial applications, dilute acid processes $\left(0.5-1.5 \%(\mathrm{w} / \mathrm{w})\right.$ acid, $\left.121-160{ }^{\circ} \mathrm{C}\right)$ have been most favored because they generally result in high hemicellulose recoveries, hydrolyze hemicellulose to monomeric sugars leaving a cellulose-enriched solid fraction. ${ }^{5-7}$ The chemical mechanism in dilute acid hydrolysis is complex, since the reaction is heterogeneous. The substrate is in the solid phase, while the catalyst is in the liquid phase.

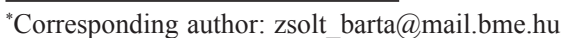

The mechanism depends on transport limitations, the effect of structure, and interactions owing to molecular forces. ${ }^{8}$ The hemicellulose hydrolysis mechanism is the following: (i) generation of protons, (ii) migration of protons to the active site, (iii) disruption of molecular interactions, (iv) diffusion of hydrolysis products through pores in lignocellulose particles, and (v) mass transfer of products into and within the bulk solution. ${ }^{9}$

Compared to concentrated acid hydrolysis, this pretreatment has several advantages: it generates less degradation products and less corrosion problems in the hydrolysis tanks. However, depending on the hydrolysis conditions applied during dilute acid pretreatment it has disadvantages, such as, the formations of inhibitor compounds like furfural, 5-hydroxymethylfurfural (HMF), acetic acid and phenolic compounds. ${ }^{2,8,9}$ During dilute acid hydrolysis of lignocellulosic residues, parameters such as temperature, time, acid concentration, and solid-to-liquid ratio play a critical role in obtaining optimum sugar recovery and low concentrations of inhibitors. ${ }^{9-11}$ Sulfuric acid is the usual acid employed, although hydrochloric acid, nitric acid and phosphoric acid can also be used. ${ }^{7}$ Sulfuric acid treatment seems to be an appropriate pretreatment for corn stover to enhance obtaining useful products in a biorefinery process.

Corn stover consists of leaves, stalks, husks, tassels, and cobs of the corn plant remaining in the 
field after the harvest of cereal grain. ${ }^{5}$ Previous studies have reported a large diversity in corn stover composition depending on both genetics and environmental factors. ${ }^{12}$ Corn stover has been investigated as a fiber source for pulp and papermaking since 1929. ${ }^{13}$ Corn stover is utilized as a raw material for bioethanol, biochemical and xylose production, which requires the effective hydrolysis of the hemicellulose content of corn stover.

Gao et al. removed $89 \%$ of the hemicellulose from corn stover with dilute sulfuric acid pretreatment with solid-liquid ratio $1: 20$ at $130{ }^{\circ} \mathrm{C}$ for 30 minutes. ${ }^{14}$ Lloyd and Wyman summarized some studies for pretreatment of corn residues. ${ }^{15}$ For corn stover, the highest xylose yield varied from $53 \%$ to $95 \%$ of the theoretical. The highest xylose yield (95\%) was obtained by Tucker et al., with $1 \%$ acid, $190{ }^{\circ} \mathrm{C}$ reaction temperature, 1.5 -minute reaction time. ${ }^{16}$

Dilute hydrochloric acid treatment of corn stover is also used for hemicellulose hydrolysis. The disadvantages of dilute hydrochloric acid treatment is that relatively high temperature is needed and inhibitory products including furfural, HMF, organic acid are generated at high reaction temperatures. ${ }^{17}$

Hydrolyzate obtained with dilute acid hydrolysis of arabinoxylan-containing materials, such as corn stover, contains arabinose besides xylose. The $\alpha-1 \rightarrow 2 / 3$ bonds connecting arabinose moieties to the xylan backbone are more sensitive to the effects of $\mathrm{pH}$ and temperature than the $\beta-1 \rightarrow 4$ bonds of the xylan, thus acid hydrolysis under mild conditions seems to be an appropriate method to selectively release a significant part of the arabinose from the hemicellulose of lignocellulosic residues. ${ }^{18,19}$

Fehér et al. investigated a selective arabinose release from corn fiber under mild conditions $\left(90^{\circ} \mathrm{C}\right.$, 5-10 minutes and $0.15-0.75 \%(\mathrm{w} / \mathrm{w})$ sulfuric acid). They reported that, at appropriately mild conditions, moderate arabinose yields were obtained with high selectivity, however, at high arabinose yields significant amounts of other sugars are also solubilized. ${ }^{21}$

The kinetics of hemicellulose hydrolysis has been investigated in many studies. ${ }^{20-26}$ Most of the models assume pseudo-homogeneous first-order reactions, and they can accurately reproduce experimental data, however, the determined parameters often apply to specific substrates and cover a narrow range of reaction conditions. Some of the models distinguish two fractions of the xylan (easy-to-hydrolyze and hard-to-hydrolyze), and both fractions have their own hydrolysis rate constants..$^{20,23,25}$ These models are referred to as biphasic models.

The present work aimed the investigation of selective xylose removal from corn stover. The goal was not only to maximize the xylose yield, but also to produce concentrated xylose solution, and to increase the xylose purity. For the latter, we report pre-hydrolyses aiming the selective arabinose removal and dilute sulfuric acid hydrolysis of arabinose reduced corn stover. To assess the efficiency of the arabinose removal and selective xylose hydrolyses, the total sugar concentrations including oligomers and monomers were used for the sugar components. The kinetic models for hemicellulose hydrolysis have been based on monomer and oligomer concentrations; however, the applicability of total sugar concentrations has not yet been demonstrated. In this study, we show that both pseudo first-order and biphasic models can be based on total sugar concentrations, which results in simple kinetic models for studying the efficiency of the arabinose removal and xylose hydrolysis.

\section{Materials and methods}

\section{Raw material analysis}

Corn stover was kindly donated by a Hungarian farmer. It was dried and chopped to less than $4 \mathrm{~mm}$. Corn stover was stored at room temperature in plastic bags.

\section{Determination of inorganic compounds}

Analytical quantity of corn stover was measured in formerly annealed crucible, and the sample was incinerated in a muffle furnace equipped with a ramping program. ${ }^{27}$ Ash content was calculated as the ratio of the weight after furnace and the original weight of the dry corn stover.

\section{Determination of glucan, xylan, arabinan and lignin} content

Determination of structural carbohydrates and lignin was accomplished using National Renewable Energy Laboratory (NREL) method with minor modifications. ${ }^{28} \mathrm{~A}$ half gram dry, ground, representative sample was mixed with $2.5 \mathrm{~mL}$ of $72 \%(\mathrm{w} / \mathrm{w})$ sulfuric acid. The mixture was kept at room temperature for 2 hours, and mixed every half hour. After 2 hours, $75 \mathrm{~mL}$ of ultrapure (milli-Q) water was added to the mixture, and this was treated for an hour at $120{ }^{\circ} \mathrm{C}$ in autoclave. The sample was then filtered on G3 glass filter with vacuum. Liquid fraction was analyzed by high-performance liquid chromatography (HPLC).

\section{Acid treatments}

Corn stover (particle size less than $4 \mathrm{~mm}$ ) was treated with sulfuric and hydrochloric acids. The re- 
actions were performed in 250-mL glass bottles filled with $100 \mathrm{~mL}$ of reaction volume. Sulfuric and hydrochloric acid treatments aimed the hydrolysis of the xylan content of corn stover.

Sulfuric acid hydrolyses at low temperatures $\left(120{ }^{\circ} \mathrm{C}\right.$ and $140{ }^{\circ} \mathrm{C}$ ) were performed in autoclave using $5 \%(\mathrm{w} / \mathrm{w}), 7 \%(\mathrm{w} / \mathrm{w})$ and $10 \%(\mathrm{w} / \mathrm{w})$ dry matter content. Acid concentration and reaction time were varied from $1.5 \%(\mathrm{w} / \mathrm{w})$ to $4 \%(\mathrm{w} / \mathrm{w})$ and from 60 to 120 minutes, respectively. The warm-up period of the autoclave from room temperature to $120{ }^{\circ} \mathrm{C}$ and $140{ }^{\circ} \mathrm{C}$ was 20 and 25 minutes, respectively. The cool-down period to $80{ }^{\circ} \mathrm{C}$ was 20 and 40 minutes after the treatments at $120^{\circ} \mathrm{C}$ and $140{ }^{\circ} \mathrm{C}$, respectively. The solid-liquid separation was performed at $80{ }^{\circ} \mathrm{C}$. Sulfuric acid hydrolyses at high temperatures $\left(150-180{ }^{\circ} \mathrm{C}\right)$ were performed in a Parr reactor using a dry matter content of $7 \%(\mathrm{w} / \mathrm{w})$. Acid concentration and reaction time were varied from $0.5 \%(\mathrm{w} / \mathrm{w})$ to $1 \%(\mathrm{w} / \mathrm{w})$ and from 5 to 10 minutes. The warm-up period of the Parr reactor from room temperature to $150-180{ }^{\circ} \mathrm{C}$ was between 35 and 55 minutes. The cool-down period was between 90 and 120 minutes. Hydrochloric acid hydrolysis experiments were performed at $120{ }^{\circ} \mathrm{C}$ using $10 \%(\mathrm{w} / \mathrm{w})$ dry matter in autoclave. Acid concentration and reaction time were varied from $2 \%(\mathrm{w} / \mathrm{w})$ to $4 \%(\mathrm{w} / \mathrm{w})$ and from 20 to 120 minutes.

Dilute sulfuric acid hydrolysis of corn stover aimed the selective release of the arabinose moieties from corn stover. The arabinose removing pre-hydrolysis experiments were performed at 90 ${ }^{\circ} \mathrm{C}$ in water bath, at 300 rotations per minute (rpm), at $7 \%(\mathrm{w} / \mathrm{w})$ dry matter using different concentrations of sulfuric acid $[0.2 \%(\mathrm{w} / \mathrm{w}) ; 0.25 \%(\mathrm{w} / \mathrm{w})$; $0.3 \%(w / w)]$ with or without soaking. Soaking was carried out for 24 hours with the acidic liquid at room temperature before the dilute sulfuric acid pre-hydrolysis at $90{ }^{\circ} \mathrm{C}$.

After acid hydrolyses, the supernatants were separated by filtration using nylon filter $(100 \mu \mathrm{m})$. The liquid fractions were analyzed by HPLC and the solid fractions were washed with $80{ }^{\circ} \mathrm{C}$ distilled water, dried at $40{ }^{\circ} \mathrm{C}$, and the glucan, xylan, arabinan and lignin contents were determined.

\section{Experiment on a pilot scale}

Pilot-scale experiment (10 L working volume) was performed in a 30-L BIOSTAT C-DCU reactor (Goettingen, Germany). The arabinose removing pre-hydrolysis was carried out with $1 \mathrm{~kg}$ corn stover and $0.3 \%(\mathrm{w} / \mathrm{w})$ sulfuric acid, at $90{ }^{\circ} \mathrm{C}$, 4-hour reaction time, $10 \%(\mathrm{w} / \mathrm{w})$ dry matter. The warm-up period of the reactor from room temperature to $120{ }^{\circ} \mathrm{C}$ was 24 minutes and the cool-down period was 96 minutes. After the arabinose removing pre-hydrolysis, the corn stover was filtered on a 50 micron nylon filter, and washed with $80^{\circ} \mathrm{C}$ distilled water. Arabinose reduced corn stover was hydrolyzed with $1.5 \%(\mathrm{w} / \mathrm{w})$ sulfuric acid, at $120{ }^{\circ} \mathrm{C}, 7$ $\%(\mathrm{w} / \mathrm{w})$ dry matter. Samples were taken every 10 minutes.

\section{Hydrolyzate recycling}

In the hydrolyzate recycling experiments, the supernatant (first hydrolyzate) obtained after the $1.5 \%(\mathrm{w} / \mathrm{w})$ sulfuric acid treatment (first hydrolysis) of corn stover, was separated from the solid fraction by vacuum filtration and reused to hydrolyze a new batch of corn stover (second hydrolysis). Both steps of the hydrolysis were carried out at $140{ }^{\circ} \mathrm{C}$ for 40 minutes at $7 \%(\mathrm{w} / \mathrm{w})$ dry matter content. After the second hydrolysis, the supernatant (second hydrolyzate) was separated from the solid fraction, and again a new batch of corn stover was hydrolyzed (third hydrolysis) under the same conditions. The aim of the hydrolyzate recycling was to increase the xylose concentration in the supernatant.

\section{Kinetic modelling}

We assumed a simple model based on the pseudo-homogeneous first-order reaction of the hydrolysis of polysaccharides into oligo- and monosaccharides, however, the sum of monosaccharides and oligosaccharides in monomer equivalent - referred to as total sugar - was considered as an overall product.

\section{Polysaccharide $\stackrel{k}{\longrightarrow}$ total sugar (sum of monomers and oligomers in monomer equivalent)}

where $k$ refers to the first-order rate constant $\left(\mathrm{min}^{-1}\right)$.

The total sugar concentrations has the advantages that 1) they merge the different solubilized forms of a particular sugar component as a single value, and 2) they directly show the efficiency of the arabinose removal and xylose hydrolyses.

The degradation of the sugar monomers is not incorporated in the model, since in the experiments used for modelling neither furfural, nor HMF were detected. When the curve fitting required the introduction of easy-to-hydrolyze and hard-to-hydrolyze fractions, the rate constant of the latter was assumed to be zero, and this assumption is the basis of the biphasic model. ${ }^{21,23}$ Curve fitting was performed using the software Berkeley Madonna (University of California, Berkeley, CA), and Runge-Kutta 4 integration method was applied.

\section{Total sugar determination}

Liquid samples were treated with $8 \%(w / w)$ sulfuric acid at a volume ratio of $1: 1$, and treated at 
$120{ }^{\circ} \mathrm{C}$ in autoclave for 15 minutes to hydrolyze oligomer sugars into monomer sugars. Glucose, xylose, arabinose concentrations were determined by HPLC using BioRad (Hercules, CA, USA) Aminex HPX-87H column $(300 \times 7.8 \mathrm{~mm})$ at $65^{\circ} \mathrm{C}$. Eluent was $5 \mathrm{mmol} \mathrm{L}^{-1}$ sulfuric acid, flow rate was

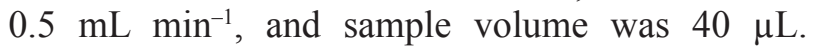
Monosaccharides were detected and quantified by refractive index. In this study, the sugar concentration is given as total sugar concentration.

\section{Acetic acid, furfural and HMF determinations}

Acetic acid, furfural and HMF concentrations were determined by the same HPLC method as described in the Total sugar determination section.

\section{Statistical analysis}

Statistical evaluation was carried out using the software Statistica 12 (Statsoft Inc., Tulsa, OK). Two mean values were compared by performing independent two-tailed $t$-tests. The probabilities, the Pearson product-moment correlation coefficients, and the coefficient of determination are denoted by $p, r$ and $R^{2}$, respectively.

\section{Results and discussion}

\section{Raw material analysis}

The results of the raw material analysis are listed in Table 1 . The main components are glucan and xylan, which contribute $37 \%$ and $25 \%$ to the dry matter, respectively. Corn stover also contains $5 \%$ arabinan, $15 \%$ lignin, and $4 \%$ inorganic compounds. The theoretical maximum amounts of xylose, glucose, and arabinose that can be released from corn stover are $28.6 \mathrm{~g}, 40.9 \mathrm{~g}$ and $8.1 \mathrm{~g}$ of $100 \mathrm{~g}$ dry matter, respectively. Sugar yield was expressed as percentage of theoretical based on the compositional analysis.

Weiss et al. reported the cellulose, xylan, and lignin content of corn stover ranging from 32.4$35.5 \%, 18.5-21.8 \%$ and $11.2-14.9 \%$, respective-

Table 1 - Corn stover compositional analysis. Standard deviations are calculated from triplicates.

\begin{tabular}{l|c|c}
\hline \multicolumn{1}{c|}{ Component } & $\begin{array}{c}\text { Percentage } \\
\text { of dry matter }\end{array}$ & $\begin{array}{c}\text { Standard } \\
\text { deviation }\end{array}$ \\
\hline Glucan & 37.2 & 0.9 \\
Xylan & 25.2 & 0.4 \\
Arabinan & 7.1 & 0.1 \\
Lignin & 15.0 & 0.1 \\
Inorganic compound & 4.0 & 0.1 \\
\hline
\end{tabular}

ly. Templeton et al. obtained cellulose, xylan and lignin contents of $26-38 \%, 15-23 \%$ and $11-17 \%$, respectively. ${ }^{29} \mathrm{Zu}$ et al. reported $39.6 \%$ glucan, $19.5 \%$ xylan, $2.0 \%$ arabinan, $1.2 \%$ galactan, 19.1 $\%$ acid-insoluble lignin and $3.1 \%$ ash contents. ${ }^{17}$ The corn stover investigated by Qin et al. contained $36.1 \%$ glucan, $20.7 \%$ xylan, $2.8 \%$ arabinan and $18.6 \%$ acid-insoluble lignin. ${ }^{30}$ In the case of the corn stover investigated in this study, xylan and arabinan contents were higher than those reported.

\section{Sulfuric acid hydrolysis}

Xylose yields obtained in sulfuric acid hydrolysis under different reaction conditions are listed in Table 2. Low temperature $\left(120^{\circ} \mathrm{C}\right)$ sulfuric acid reactions resulted in $81.1 \%$ xylose yield $(23.3 \mathrm{~g} / 100 \mathrm{~g}$ dry matter) at 60-minute reaction time, $4 \%(\mathrm{w} / \mathrm{w})$ sulfuric acid concentration, and $5 \%(\mathrm{w} / \mathrm{w})$ dry matter. High $(4 \%, w / w)$ acid concentration hydrolysis probably breaks down the cellulose structure, since glucose yield was $22 \%$ of the theoretical under the same reaction conditions. At $120{ }^{\circ} \mathrm{C}, 10 \%(\mathrm{w} / \mathrm{w})$ dry matter, and at $2 \%(\mathrm{w} / \mathrm{w})$ sulfuric acid concentration, the increasing reaction time (60-120 minutes) resulted in higher xylose yield (69.4-71.1\%). However, at $120{ }^{\circ} \mathrm{C}, 10 \%(\mathrm{w} / \mathrm{w})$ dry matter, and 4 $\%(\mathrm{w} / \mathrm{w})$ sulfuric acid concentration, the xylose yield decreased $(75.6-72.3 \%)$, while the reaction time increased (60-120 minutes). At $2 \%(w / w)$ and $4 \%(\mathrm{w} / \mathrm{w})$ sulfuric acid concentration, high xylose yields were coupled with high degradation components yields. Low temperature sulfuric acid hydrolysis showed that at $10 \%(\mathrm{w} / \mathrm{w})$ dry matter, liquid could not impregnate corn stover, although xylose yields did not show significant difference at $5 \%$ $(\mathrm{w} / \mathrm{w})$ and $10 \%(\mathrm{w} / \mathrm{w})$ dry matter $(p=0.07)$.

High temperature sulfuric acid reactions were performed with $0.5-1.5 \%(\mathrm{w} / \mathrm{w})$ sulfuric acid concentration, $7 \%(\mathrm{w} / \mathrm{w})$ dry matter, and the reaction temperature was varied from 140 to $180{ }^{\circ} \mathrm{C}$. At high temperature sulfuric acid treatment, $81.9 \%$ (23.5 g/100 g dry matter) xylose yield was obtained. In this case, $14 \%$ (5.9 g/100 g dry matter) glucose yield was obtained. At $140{ }^{\circ} \mathrm{C}$ and $1.5 \%$ (w/w) sulfuric acid hydrolysis, the yield of xylose increased by decreasing the reaction time. The same, $81.1 \%$ xylose yield were obtained at $140{ }^{\circ} \mathrm{C}$ (60 minutes, $1.5 \%$ (w/w) sulfuric acid, $7 \%$ (w/w) dry matter), and at $120{ }^{\circ} \mathrm{C}\left(60{ }^{\circ} \mathrm{C}, 4 \%\right.$ (w/w) sulfuric acid, $5 \%$ $(\mathrm{w} / \mathrm{w})$ dry matter) sulfuric acid hydrolysis. Hence, at slightly higher temperature, significantly lower amount of acid was needed. Reducing the quantity of the acid has several advantages: chemical cost reduction, less alkali needed to neutralize, and less by-products are created during the neutralization. Acetic acid appears at $140{ }^{\circ} \mathrm{C}$ in the hydrolysis solution, and 2.5-2.9 g/100 g dry matter yields were 
Table 2 -Reaction conditions, total sugar yields and degradation component yields of corn stover sulfuric acid hydrolysis. Standard deviations are calculated from duplicates. HMF: hydroxymethylfurfural. na: not analyzed.

\begin{tabular}{c|c|c|c|c|c|c|c|c|c|c}
\hline $\begin{array}{c}\text { Temp. } \\
\left({ }^{\circ} \mathrm{C}\right)\end{array}$ & $\begin{array}{c}\text { Dry } \\
\text { matter } \\
(\%)\end{array}$ & $\begin{array}{c}\text { Time } \\
(\mathrm{min})\end{array}$ & $\begin{array}{c}\text { Acid conc. } \\
(\%, \mathrm{w} / \mathrm{w})\end{array}$ & $\begin{array}{c}\text { Glucose } \\
(\mathrm{g} / 100 \mathrm{~g} \text { dry } \\
\text { matter })\end{array}$ & $\begin{array}{c}\text { Arabinose } \\
(\mathrm{g} / 100 \mathrm{~g} \text { dry } \\
\text { matter })\end{array}$ & $\begin{array}{c}\text { Xylose } \\
(\mathrm{g} / 100 \mathrm{~g} \text { dry } \\
\text { matter })\end{array}$ & $\begin{array}{c}\text { Xylose } \\
(\%)\end{array}$ & $\begin{array}{c}\text { Acetic acid } \\
(\mathrm{g} / 100 \mathrm{~g} \text { dry } \\
\text { matter })\end{array}$ & $\begin{array}{c}\text { HMF } \\
(\mathrm{g} / 100 \mathrm{~g} \\
\text { dry matter })\end{array}$ & $\begin{array}{c}\text { Furfural } \\
(\mathrm{g} / 100 \mathrm{~g} \\
\text { dry matter })\end{array}$ \\
\hline 120 & 5 & 60 & 2 & $4.6(0.2)$ & $3.9(0.04)$ & $21.9(0.2)$ & 76.4 & $0.0(0.0)$ & $0.0(0.0)$ & $0.1(0.0)$ \\
120 & 10 & 60 & 2 & $3.7(0.5)$ & $4.6(0.3)$ & $19.9(1.7)$ & 69.4 & na & na & na \\
120 & 10 & 120 & 2 & $4.5(0.3)$ & $5.1(0.3)$ & $20.4(1.1)$ & 71.1 & $0.1(0.0)$ & $0.0(0.0)$ & $0.3(0.1)$ \\
120 & 5 & 60 & 4 & $9.0(0.4)$ & $5.1(0.3)$ & $23.3(1.0)$ & 81.1 & $0.1(0.0)$ & $0.0(0.0)$ & $0.6(0.0)$ \\
120 & 10 & 60 & 4 & $4.5(0.4)$ & $5.3(0.3)$ & $21.7(0.9)$ & 75.6 & na & na & na \\
120 & 10 & 120 & 4 & $5.2(0.5)$ & $5.5(0.2)$ & $20.7(0.7)$ & 72.3 & $0.2(0.0)$ & $0.0(0.0)$ & $0.9(0.1)$ \\
140 & 7 & 40 & 1.5 & $5.9(0.7)$ & $4.6(0.7)$ & $23.5(0.1)$ & 81.9 & $2.6(0.5)$ & $0.0(0.0)$ & $0.5(0.1)$ \\
140 & 7 & 60 & 1.5 & $6.1(0.8)$ & $4.6(0.3)$ & $23.3(0.7)$ & 81.1 & $2.5(0.2)$ & $0.0(0.0)$ & $0.6(0.3)$ \\
150 & 7 & 5 & 1 & $7.5(1.2)$ & $4.8(2.8)$ & $21.0(0.2)$ & 73.2 & $2.7(0.0)$ & $0.3(0.0)$ & $0.5(0.0)$ \\
150 & 7 & 10 & 1 & $6.3(1.2)$ & $5.7(1.1)$ & $20.8(2.2)$ & 72.6 & $2.9(0.5)$ & $0.4(0.2)$ & $1.0(0.6)$ \\
160 & 7 & 5 & 0.5 & $6.3(0.1)$ & $4.6(0.7)$ & $20.0(1.3)$ & 69.9 & $2.1(0.1)$ & $0.2(0.0)$ & $0.3(0.0)$ \\
160 & 7 & 10 & 0.5 & $4.5(0.4)$ & $4.8(1.3)$ & $20.6(0.8)$ & 71.6 & $1.6(0.3)$ & $0.1(0.0)$ & $0.3(0.1)$ \\
160 & 7 & 5 & 1 & $7.4(0.4)$ & $4.5(0.1)$ & $19.9(0.9)$ & 69.2 & $3.2(0.3)$ & $0.2(0.1)$ & $0.5(0.2)$ \\
160 & 7 & 10 & 1 & $6.2(0.1)$ & $4.8(1.2)$ & $18.3(0.8)$ & 63.9 & $1.9(0.3)$ & $0.2(0.0)$ & $1.0(0.1)$ \\
170 & 7 & 5 & 0.5 & $6.7(0.6)$ & $4.0(0.6)$ & $18.8(1.5)$ & 65.4 & $2.4(0.0)$ & $0.3(0.0)$ & $0.6(0.1)$ \\
180 & 7 & 10 & 0.5 & $9.1(0.2)$ & $2.6(0.2)$ & $9.9(0.7)$ & 34.3 & $1.9(0.1)$ & $0.2(0.0)$ & $2.6(0.1)$ \\
180 & 7 & 10 & 1 & $13.3(0.2)$ & $1.7(0.5)$ & $3.6(0.3)$ & 12.5 & $1.7(0.2)$ & $0.2(0.0)$ & $2.5(0.1)$ \\
\hline
\end{tabular}

obtained. A significant correlation $(r=0.71, p=$ $0.003)$ exists between the acetic acid and HMF, which indicates that the release of acetic acid escalates under harsher conditions. At high temperature $\left(150-160{ }^{\circ} \mathrm{C}\right)$ and $0.5 \%(\mathrm{w} / \mathrm{w})$ sulfuric acid, increasing the reaction time increased the xylose yield, however, at $1 \%(\mathrm{w} / \mathrm{w})$ sulfuric acid and high temperature, increasing the reaction time had an opposite effect on the xylose yield. The xylose yield obtained at $160{ }^{\circ} \mathrm{C}, 1 \%(\mathrm{w} / \mathrm{w})$ sulfuric acid concentration, 10 minutes reaction time did not significantly differ from that obtained at $170{ }^{\circ} \mathrm{C}, 0.5 \%(\mathrm{w} / \mathrm{w})$ sulfuric acid concentration, 5 minutes $(p=0.23)$. These results showed that, with temperature increase, less acid was needed to obtain the same xylose yield. Degradation components were also measured during the hydrolysis. Between $120{ }^{\circ} \mathrm{C}$ and $170{ }^{\circ} \mathrm{C}$, the degradation component - HMF, furfural - yields were lower than $1 \mathrm{~g} / 100 \mathrm{~g}$ dry matter (Table 2). At $180{ }^{\circ} \mathrm{C}, 10$ minutes reaction time and $1 \%$ $(\mathrm{w} / \mathrm{w})$ sulfuric acid concentration, only $12.5 \% \mathrm{xy}-$ lose yield was obtained, since the xylose probably degraded to a great extent under the harsh reaction conditions. In this work, the goal was also to solubilize xylose selectively from the corn stover. Hence, selectivity $(S)$ was calculated as a ratio of xylose concentration to total sugars (glucose, arabinose and xylose) concentration. The highest selec- tivity $(S=0.72)$ was achieved at $120{ }^{\circ} \mathrm{C}, 2 \%(\mathrm{w} / \mathrm{w})$ sulfuric acid concentration, 60-minute reaction time and at $5 \%(\mathrm{w} / \mathrm{w})$ dry matter. At $140{ }^{\circ} \mathrm{C}$ reaction temperature, selectivity was 0.7 . The lowest selectivity was obtained at $180{ }^{\circ} \mathrm{C}$ reaction temperature. Lu et al. obtained 0.73 selectivity [xylose/(glucose and xylose)] at $100{ }^{\circ} \mathrm{C}, 5.5 \%(\mathrm{w} / \mathrm{w})$ sulfuric acid concentration, 60-minute reaction time, although arabinose concentration was not mentioned.$^{31} \mathrm{In}$ another paper, Dominguez et al. reported selectivity 0.87 , at $100{ }^{\circ} \mathrm{C}, 2 \%(\mathrm{w} / \mathrm{w})$ sulfuric acid, solid to liquid ratio 1:4 and 2-hour reaction time. ${ }^{32}$

\section{Hydrochloric acid hydrolysis}

The results of hydrochloric acid hydrolysis are given in Table 3. Hydrochloric acid hydrolysis with $2 \%(\mathrm{w} / \mathrm{w})$ acid concentration, 40-minute reaction time resulted in $88.8 \%$ xylose yield, and the yields of degradation components were low $(0.1 \mathrm{~g} / 100 \mathrm{~g}$ dry matter) (Table 3$)$. At $2 \%(\mathrm{w} / \mathrm{w})$ hydrochloric acid concentration, high xylose yield (79.4-88.8\%) was obtained in a short reaction time (20-40 minutes). In the case of hydrochloric acid reactions with $2 \%(\mathrm{w} / \mathrm{w})$ acid concentration and more than 40-minute reaction time, xylose degradation compounds were obtained. At $2 \%(\mathrm{w} / \mathrm{w})$ hydrochloric acid hydrolysis and 60-minute reaction time, $17 \%$ 
Table 3 -Reaction conditions, total sugar yields and degradation component yields of corn stover hydrochloric acid hydrolysis at $120^{\circ} \mathrm{C}$. Standard deviations are calculated from duplicates. HMF: hydroxymethylfurfural.

\begin{tabular}{c|c|c|c|c|c|c|c|c}
\hline $\begin{array}{c}\text { Time } \\
(\mathrm{min})\end{array}$ & $\begin{array}{c}\text { Acid conc. } \\
(\%, \mathrm{w} / \mathrm{w})\end{array}$ & $\begin{array}{c}\text { Glucose } \\
(\mathrm{g} / 100 \mathrm{~g} \text { dry } \\
\text { matter })\end{array}$ & $\begin{array}{c}\text { Arabinose } \\
(\mathrm{g} / 100 \mathrm{~g} \text { dry } \\
\text { matter })\end{array}$ & $\begin{array}{c}\text { Xylose } \\
(\mathrm{g} / 100 \mathrm{~g} \text { dry } \\
\text { matter })\end{array}$ & $\begin{array}{c}\text { Xylose } \\
(\%)\end{array}$ & $\begin{array}{c}\text { Acetic acid } \\
(\mathrm{g} / 100 \mathrm{~g} \text { dry } \\
\text { matter })\end{array}$ & $\begin{array}{c}\text { HMF } \\
(\mathrm{g} / 100 \mathrm{~g} \text { dry } \\
\text { matter })\end{array}$ & $\begin{array}{c}\text { Furfural } \\
(\mathrm{g} / 100 \mathrm{~g} \text { dry } \\
\text { matter })\end{array}$ \\
\hline 20 & 2 & $5.0(0.0)$ & $6.4(0.5)$ & $22.8(0.6)$ & 79.4 & $0.0(0.0)$ & $0.0(0.0)$ & $0.0(0.0)$ \\
40 & 2 & $6.2(0.0)$ & $8.0(0.1)$ & $25.5(0.2)$ & 88.8 & $0.0(0.0)$ & $0.0(0.0)$ & $0.0(0.0)$ \\
60 & 2 & $5.6(0.1)$ & $5.6(0.5)$ & $20.5(1.4)$ & 71.3 & $0.1(0.0)$ & $0.0(0.0)$ & $0.9(0.1)$ \\
120 & 2 & $4.7(0.1)$ & $5.1(0.1)$ & $17.1(0.6)$ & 59.8 & $0.2(0.0)$ & $0.0(0.0)$ & $1.3(0.0)$ \\
60 & 4 & $5.9(0.0)$ & $5.4(0.1)$ & $16.0(0.3)$ & 55.8 & $0.3(0.0)$ & $0.0(0.0)$ & $2.0(0.0)$ \\
120 & 4 & $6.7(0.8)$ & $4.5(1.3)$ & $11.7(1.9)$ & 40.9 & $1.2(0.2)$ & $0.0(0.0)$ & $2.8(0.1)$ \\
\hline
\end{tabular}

less xylose yield was obtained than at $2 \%(\mathrm{w} / \mathrm{w})$ hydrochloric acid and 40-minute reaction time $(p=0.09)$. At $2 \%(\mathrm{w} / \mathrm{w})$ hydrochloric acid reactions, $0.9 \mathrm{~g} / 100 \mathrm{~g}$ dry matter, furfural was obtained. Degradation component yield increased by increasing the reaction time. Xylose yield decreased at long reaction time (60-120 minutes). At $4 \%(\mathrm{w} / \mathrm{w})$ hydrochloric acid, approximately two-times higher furfural yields were obtained than at $2 \%(\mathrm{w} / \mathrm{w})$ hydrochloric acid hydrolysis during the same time $(p=0.14$ and 0.12 , respectively). Hence, xylose degraded to a greater extent at $4 \%(\mathrm{w} / \mathrm{w})$ acid concentration than at $2 \%(\mathrm{w} / \mathrm{w})$ acid concentration.

In the tested reaction conditions with hydrochloric acid the highest, $98.7 \%$ arabinose yield was obtained at $2 \%(\mathrm{w} / \mathrm{w})$ acid concentration, and 40 -minute reaction time. Glucose yields varied from 11 to $16 \%$ of the theoretical. Selectivity of the hydrochloric acid reactions was calculated as xylose to total sugars ratio. The highest $(S=0.67)$ selectivity was obtained at $120{ }^{\circ} \mathrm{C}, 2 \%(\mathrm{w} / \mathrm{w})$ hydrochloric acid and 20-minute reaction time. Higher selectivity was obtained at mild conditions. Dominguez et al. obtained 0.85 selectivity at $100{ }^{\circ} \mathrm{C}, 2 \%(\mathrm{w} / \mathrm{w})$ hydrochloric acid concentration and 2-hour reaction time. ${ }^{32}$

Hydrochloric acid hydrolysis reaction worked differently than the reactions with sulfuric acid. In the case of sulfuric acid, significant xylose degradation started at high reaction temperature $\left(170-180^{\circ} \mathrm{C}\right)$. At $2 \%(\mathrm{w} / \mathrm{w})$ hydrochloric acid concentration, and 60-minute reaction time, $71.3 \%$ xylose yield and $2.0 \mathrm{~g} / 100 \mathrm{~g}$ dry matter furfural were obtained. At $2 \%$ $(\mathrm{w} / \mathrm{w})$ acid concentration, 120 minutes, only $59.8 \%$ xylose yield was obtained together with $2.8 \mathrm{~g} / 100 \mathrm{~g}$ dry matter furfural (Table 3), which indicated that the xylose degradation depended on the reaction time. Hydrolysis with $4 \%(\mathrm{w} / \mathrm{w})$ hydrochloric acid further increased the xylose degradation. A significant correlation $(r=0.82, p=0.044)$ is obtained between the acetic acid and furfural, which indicates that similarly to the sulfuric acid hydrolyses, the release of acetic acid increases under more severe conditions.

$\mathrm{Zu}$ et al. pretreated corn stover under different conditions with $1 \%(\mathrm{w} / \mathrm{w})$ hydrochloric acid at relatively high reaction temperature $\left(100-130{ }^{\circ} \mathrm{C}\right)$. Xylose yield ranged from 14.9 to $20.4 \mathrm{~g} / 100 \mathrm{~g}$ raw material. The maximum xylose yield $(92.2 \%$ of the theoretical) was obtained at $120{ }^{\circ} \mathrm{C}$ and 40 -minute reaction time. As the pretreatment severity increased, the xylose yield decreased due to the xylose degradation into furfural or other by-products, although degradation compounds were not reported. Glucose yield varied from $0.59 \mathrm{~g} / 100 \mathrm{~g}$ raw material $\left(100{ }^{\circ} \mathrm{C}\right.$ and 20 minutes) to $2.33 \mathrm{~g} / 100 \mathrm{~g}$ raw material $\left(130{ }^{\circ} \mathrm{C}\right.$ and 40 minutes $) .{ }^{17}$

\section{Hydrolyzate recycling}

Concentration of xylose solution can be carried out with the recycling of the hydrolyzate. Sulfuric acid hydrolysis results showed that sulfuric acid did not degrade xylose considerably at low sulfuric acid concentration (less than $2 \%, \mathrm{w} / \mathrm{w}$ ) and low temperature $\left(120-140{ }^{\circ} \mathrm{C}\right)$ (Table 2). Therefore, the supernatant can be used for hydrolyzing a new batch of corn stover. By hydrolyzate recycling, the xylose concentration increased, however, the concentrations of other components (e.g. glucose, arabinose, furfural, HMF, acetic acid) also increased. Hydrolyzate recycling results are given in Table 4 . The hydrolyzed sugar yields are calculated from the amount of corn stover used during the given hydrolysis step. Although the xylose yield of hydrolysis \#1 is lower than that obtained under the same conditions and shown in Table 2, there is no significant difference between these xylose yields ( $p=0.07$ ). Table 4 lists the hydrolyzed sugar yields that did not change significantly in each step. Hence, at the end of the third hydrolysis, the xylose concentration was approximately three-times higher than that after the first hydrolysis. The third hydrolyzate contained $47 \mathrm{~g} \mathrm{~L}^{-1}$ xylose, $11.6 \mathrm{~g} \mathrm{~L}^{-1}$ glucose and $7.3 \mathrm{~g} \mathrm{~L}^{-1}$ arabinose. 
Table 4 - Total sugar yields in g/100 $\mathrm{g}$ dry matter and xylose yields (\% of the theoretical) of corn stover sulfuric acid hydrolysis in hydrolyzate recycling. The hydrolyzate recycling experiments were carried out at $140{ }^{\circ} \mathrm{C}$ reaction temperature, 40 -minute reaction time and $7 \%(w / w)$ dry matter. Standard deviations are calculated from duplicates.

\begin{tabular}{c|c|c|c|c}
\hline Hydrolysis & $\begin{array}{c}\text { Glucose } \\
(\mathrm{g} / 100 \mathrm{~g} \text { dry matter })\end{array}$ & $\begin{array}{c}\text { Arabinose } \\
(\mathrm{g} / 100 \mathrm{~g} \text { dry matter })\end{array}$ & $\begin{array}{c}\text { Xylose } \\
(\mathrm{g} / 100 \mathrm{~g} \text { dry matter })\end{array}$ & $\begin{array}{c}\text { Xylose } \\
(\%)\end{array}$ \\
\hline$\# 1$ & $5.0(0.3)$ & $3.2(0.2)$ & $21.1(1.0)$ & 73.4 \\
$\# 2$ & $4.9(0.1)$ & $3.0(0.0)$ & $20.1(0.3)$ & 69.9 \\
$\# 3$ & $5.1(0.5)$ & $3.2(0.3)$ & $20.8(1.6)$ & 72.6 \\
\hline
\end{tabular}

\section{Arabinose removing pre-hydrolysis}

Acid hydrolysis is a simple method for the liberation of monosaccharides from hemicellulose, hence the yields of the products, the ratio of arabinose to xylose, could be easily controlled by choosing conditions, such as the type and concentration of acid, and the period and temperature of hydrolysis. ${ }^{33}$ In our work, the purpose of arabinose removing pre-hydrolysis experiments was to enhance the xylose selectivity in the hydrolysis experiments. Arabinose removing pre-hydrolysis was performed at $0.2 \%(\mathrm{w} / \mathrm{w}), 0.25 \%(\mathrm{w} / \mathrm{w})$, and $0.3 \%(\mathrm{w} / \mathrm{w})$ sulfuric acid concentration based on the results of Fehér et. al. ${ }^{21}$ Results of sulfuric acid hydrolysis carried out with $0.2 \%(\mathrm{w} / \mathrm{w})$ acid concentration are shown in Figure 1. In the case of pre-hydrolysis without soaking, the initial yields were greater than zero. This can be explained by the following: the raw material was thoroughly mixed with the $90{ }^{\circ} \mathrm{C}$ acid solution, and then the zero-time sample was withdrawn and centrifuged. The supernatant could contain some oligomers, which were then hydrolyzed during the total sugar determination giving significant total sugar concentrations.

In the case of arabinose removing pre-hydrolysis carried out with $0.2 \%(\mathrm{w} / \mathrm{w})$ sulfuric acid, the yields of glucose, xylose, and arabinose were $11.9 \%$, $13.1 \%$, and $19.8 \%$, respectively, after 8 -hour acid hydrolysis (Figure 1a). In the case of 24-hour soaking before hydrolysis, glucose, xylose and arabinose yields were $13.3 \%, 14.2 \%$, and $22.9 \%$, respectively (Figure 1b). The arabinose yield within 3 -hour acid hydrolysis was lower than the glucose and $\mathrm{xy}-$ lose yields. After 4-hour reaction, arabinose yield increased faster than the yields of glucose and $\mathrm{xy}-$ lose.

Results of sulfuric acid hydrolysis carried out with $0.25 \%(\mathrm{w} / \mathrm{w})$ acid concentration are shown in Figure 2. In the case of $0.25 \%(\mathrm{w} / \mathrm{w})$ sulfuric acid hydrolysis at 8-hour reaction time, glucose, xylose and arabinose yields were $13.4 \%, 15.6 \%$, and $33.8 \%$, respectively. Soaked in $0.25 \%$ (w/w) sulfuric acid corn stover hydrolysis results are shown in Figure $2 \mathrm{~b}$. After 8-hour reaction time, glucose, $x y-$ lose, and arabinose yields were $13.6 \%, 16.1 \%$, and $28.8 \%$, respectively. In the case of $0.25 \%(\mathrm{w} / \mathrm{w})$ sulfuric acid hydrolysis at the 2.5 -hour reaction time, higher arabinose yield was obtained than that of xylose or glucose, while in the case of arabinose removing pre-hydrolysis with $0.2 \%(\mathrm{w} / \mathrm{w})$ sulfuric acid, arabinose yield overtook glucose and xylose yields at 3-hour reaction time. Arabinose yield grew faster at higher sulfuric acid concentration. The hydrolysis profiles are similar in both cases (Figures $2 \mathrm{a}$ and $2 \mathrm{~b})$. Comparing $0.2 \%(\mathrm{w} / \mathrm{w})$ and $0.25 \%$ (w/w) sulfuric acid hydrolyses, higher acid concentration results in higher sugar yield in the hydrolyzate.
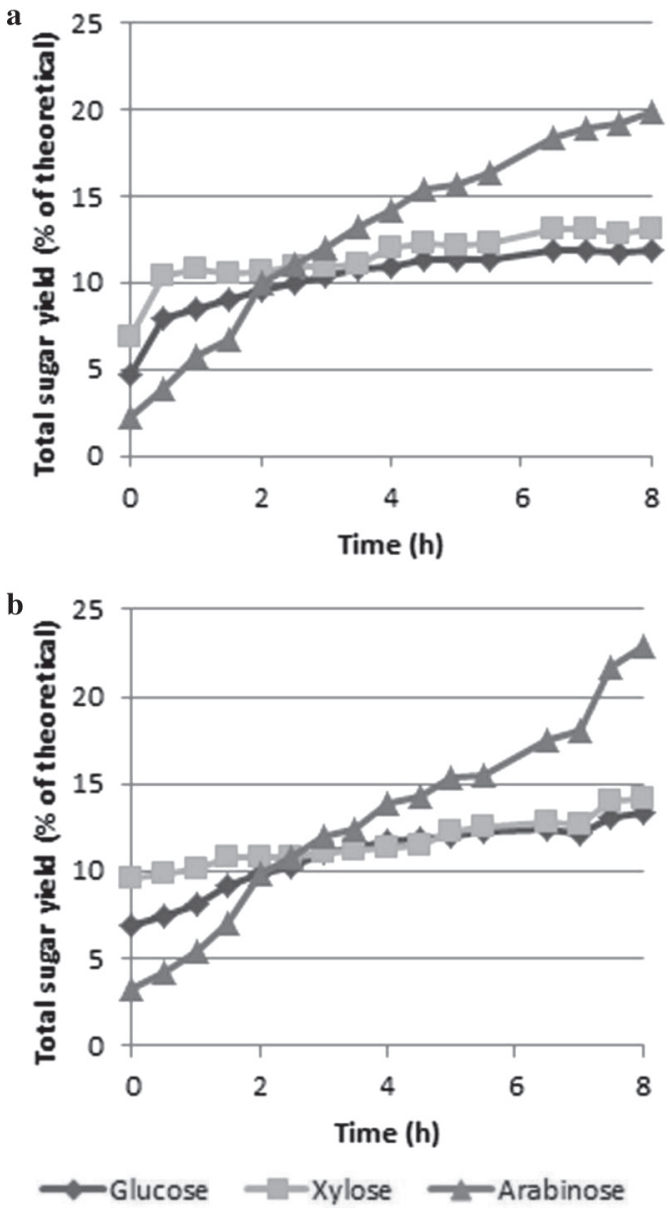

Fig. 1 - Arabinose removing pre-hydrolysis at $90{ }^{\circ} \mathrm{C}$ and $7 \%(w / w)$ dry matter using $0.2 \%(w / w)$ sulfuric acid $(a)$, and arabinose removing pre-hydrolysis at $90{ }^{\circ} \mathrm{C}$ and $7 \%(\mathrm{w} / \mathrm{w})$ dry matter using $0.2 \%(w / w)$ sulfuric acid after 24 hours soaking of the raw material in the acidic liquid (b) 


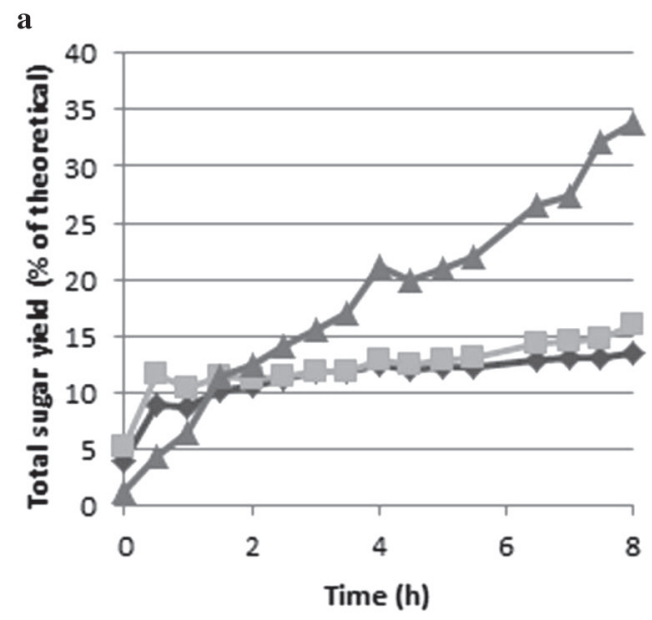

b

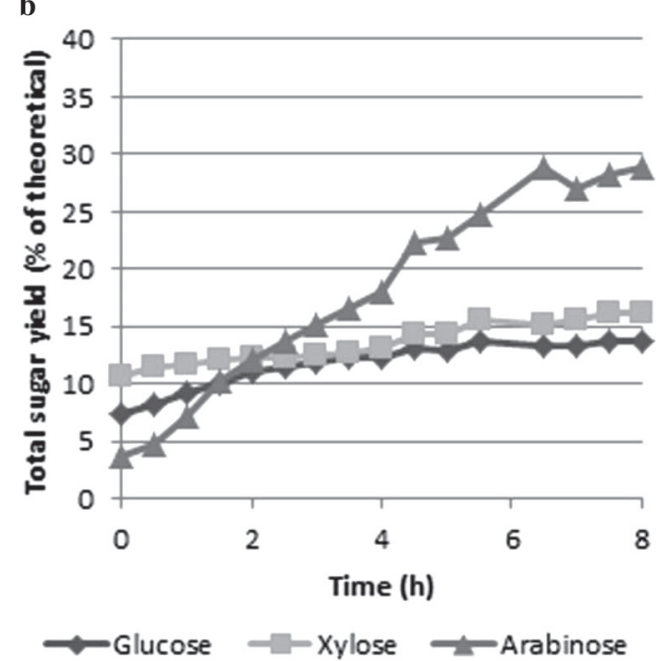

Fig. 2 - Arabinose removing pre-hydrolysis at $90{ }^{\circ} \mathrm{C}$ and $7 \%(w / w)$ dry matter using $0.25 \%(w / w)$ sulfuric acid (a), and arabinose removing pre-hydrolysis at $90{ }^{\circ} \mathrm{C}$ and $7 \%(w / w)$ dry matter using $0.25 \%(w / w)$ sulfuric acid after 24 hours soaking of the raw material in the acidic liquid (b)

Results of arabinose removing pre-hydrolysis carried out with $0.3 \%(\mathrm{w} / \mathrm{w})$ sulfuric acid concentration are shown in Figure 3. In the case of $0.3 \%$ $(\mathrm{w} / \mathrm{w})$ sulfuric acid hydrolysis (Figure $3 \mathrm{a})$, the results are $14.5 \%$ glucose yield, $18.7 \%$ xylose yield, and $38.2 \%$ arabinose yield at 8 -hour reaction time. In the case of soaking after 8-hour hydrolysis, $14.0 \%$ glucose, $18.3 \%$ xylose, and $37.8 \%$ arabinose yields were obtained (Figure $3 b)$. At $0.3 \%(w / w)$ sulfuric acid hydrolysis, arabinose yield is higher than glucose and xylose yields at 2-hour reaction time.

Separate curve fitting was performed for each dataset of the arabinose removing pre-hydrolyses, and obtained $k$ values are listed in Table 5. In the case of arabinose, the pseudo first-order rate equation resulted in high $R^{2}$ values, which indicated high level of accuracy. At a given acid concentration, the $k$ values of arabinose formation with soaking do not significantly differ from those without soaking. In
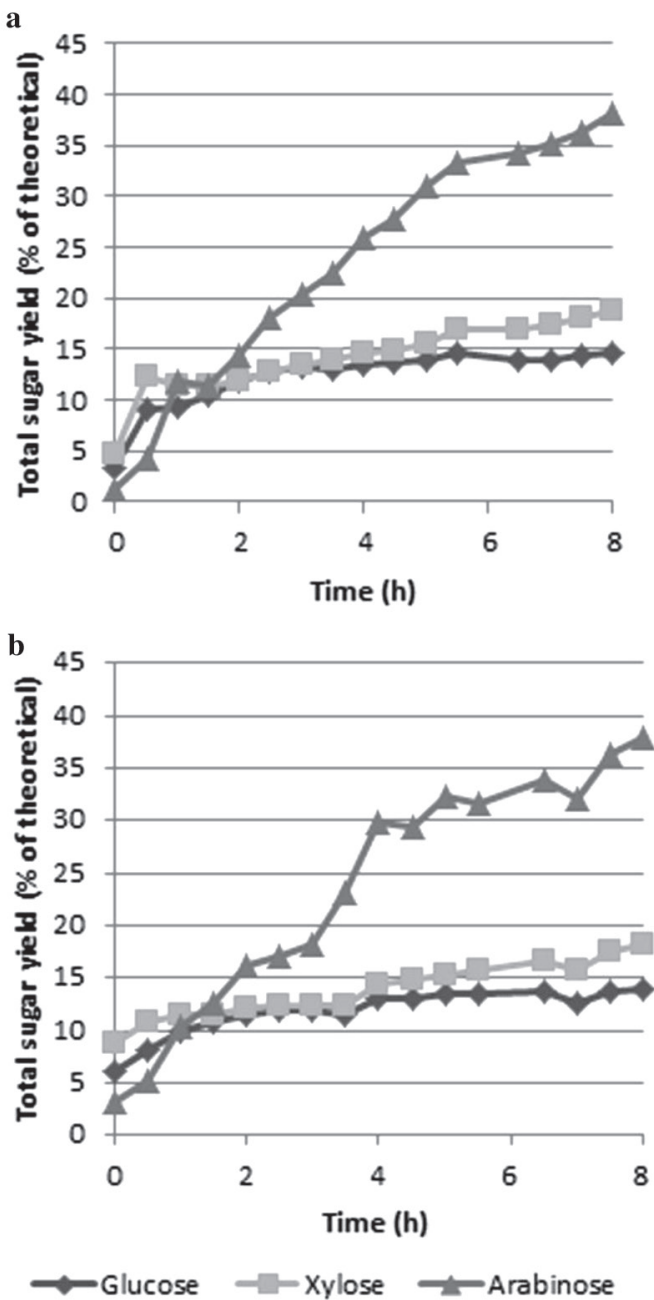

Fig. 3 - Arabinose removing pre-hydrolysis at $90{ }^{\circ} \mathrm{C}$ and $7 \%(w / w)$ dry matter using $0.3 \%(w / w)$ sulfuric acid $(a)$, and arabinose removing pre-hydrolysis at $90{ }^{\circ} \mathrm{C}$ and $7 \%(w / w)$ dry matter using $0.3 \%(w / w)$ sulfuric acid after 24 hours soaking of the raw material in the acidic liquid (b)

the case of glucose, the pseudo first-order model did not fit properly neither with nor without soaking, and the biphasic model could result in acceptable $R^{2}$ values. The pseudo first-order model could not predict well the formation of xylose without soaking. However, when soaking was applied, the formation of xylose followed pseudo first-order kinetics, which implies that the soaking could convert the whole xylan fraction into an easy-to-hydrolyze fraction. By applying the biphasic model for the formation of xylose, the $R^{2}$ values increased only moderately compared to those obtained with the pseudo first-order model, which was due to the large deviation between the predicted and experimental data in the first phase of the reaction (0-4 hours). In the second phase (4-8 hours), good fits were observed (data not shown). The $k$ values of the formation of all the components increased by increasing the acid concentration, which was due to 
Table 5 -Model parameters for the arabinose removing pre-hydrolyses

\begin{tabular}{|c|c|c|c|c|c|c|c|c|c|}
\hline Acid concentration $(\%)$ & & 0.2 & & & 0.25 & & & 0.3 & \\
\hline Soaking & & No & & & No & & & No & \\
\hline component & Glucose & Xylose & Arabinose & Glucose & Xylose & Arabinose & Glucose & Xylose & Arabinose \\
\hline$k$, first-order $\left(\mathrm{min}^{-1}\right)$ & $2.1 \cdot 10^{-4}$ & $1.7 \cdot 10^{-4}$ & $4.6 \cdot 10^{-4}$ & $2.8 \cdot 10^{-4}$ & $2.7 \cdot 10^{-4}$ & $7.9 \cdot 10^{-4}$ & $3.4 \cdot 10^{-4}$ & $3.7 \cdot 10^{-4}$ & $1.1 \cdot 10^{-4}$ \\
\hline$R^{2}$ & 0.76 & 0.76 & 0.96 & 0.70 & 0.74 & 0.98 & 0.66 & 0.84 & 0.98 \\
\hline$k$, first-order, biphasic $\left(\min ^{-1}\right)^{*}$ & $3.0 \cdot 10^{-3}$ & $1.7 \cdot 10^{-3}$ & - & $6.0 \cdot 10^{-3}$ & $3.0 \cdot 10^{-3}$ & - & $1.3 \cdot 10^{-2}$ & $6.0 \cdot 10^{-3}$ & - \\
\hline$R^{2}$ & 0.87 & 0.80 & - & 0.89 & 0.76 & - & 0.96 & 0.85 & - \\
\hline Acid concentration $(\%)$ & & 0.2 & & & 0.25 & & & 0.3 & \\
\hline Soaking & & Yes & & & Yes & & & Yes & \\
\hline component & Glucose & Xylose & Arabinose & Glucose & Xylose & Arabinose & Glucose & Xylose & Arabinose \\
\hline$k$, first-order $\left(\mathrm{min}^{-1}\right)$ & $1.6 \cdot 10^{-4}$ & $8.7 \cdot 10^{-5}$ & $4.3 \cdot 10^{-4}$ & $1.8 \cdot 10^{-4}$ & $1.2 \cdot 10^{-4}$ & $6.7 \cdot 10^{-4}$ & $2.2 \cdot 10^{-4}$ & $2.1 \cdot 10^{-4}$ & $9.8 \cdot 10^{-4}$ \\
\hline$R^{2}$ & 0.89 & 0.95 & 0.97 & 0.85 & 0.96 & 0.98 & 0.74 & 0.95 & 0.95 \\
\hline$k$, first-order, biphasic $\left(\min ^{-1}\right)^{*}$ & $2.0 \cdot 10^{-3}$ & - & - & $2.0 \cdot 10^{-3}$ & - & - & $3.0 \cdot 10^{-3}$ & - & - \\
\hline$R^{2}$ & 0.95 & - & - & 0.92 & - & - & 0.86 & - & - \\
\hline
\end{tabular}

*Easy-to-hydrolyze fractions ( 0.146 and 0.187 for glucose and xylose, respectively) were estimated based on the highest yields obtained in the arabinose removal hydrolyses.

the more severe reaction conditions, under which the hydrolyses become faster.

The 24-hour soaking of the raw material in the acidic liquid before hydrolysis did not increase the arabinose yield significantly compared to sulfuric acid hydrolysis without soaking. Results demonstrate that dilute sulfuric acid hydrolysis supports arabinose removal. Comparing $0.2 \%(\mathrm{w} / \mathrm{w})$ and $0.3 \%(\mathrm{w} / \mathrm{w})$ sulfuric acid hydrolysis, $15 \%$ higher xylose yield was obtained at 8-hour reaction time with $0.3 \%(\mathrm{w} / \mathrm{w})$ sulfuric acid hydrolysis. The goal of arabinose removing pre-hydrolysis was to solubilize arabinose, while keeping xylose in the solid fraction. In the case of $0.3 \%(\mathrm{w} / \mathrm{w})$ sulfuric acid hydrolysis at 8-hour reaction time, $37.8 \%$ arabinose yield was obtained together with $18.7 \%$ xylose yield. We arbitrarily chose a $15 \%$-limit for the xylose yield in arabinose removing pre-hydrolysis. Xylose yield was $14.6 \%$ and $26.0 \%$ arabinose yield was obtained at $0.3 \%(\mathrm{w} / \mathrm{w})$ sulfuric acid concentration and 4-hour reaction time, hence these conditions were chosen for scaling up the arabinose removing pre-hydrolysis on a pilot scale.

\section{Experiment on a pilot scale}

With the arabinose removing pre-hydrolysis (data not shown) $2 \mathrm{~g} \mathrm{~L}^{-1}$ and $5.6 \mathrm{~g} \mathrm{~L}^{-1}$ arabinose and glucose was removed, respectively, which means $25.7 \%$ arabinose and $12.1 \%$ glucose of the theoretical. The hydrolysis aiming at arabinose removal results in $4.0 \mathrm{~g} \mathrm{~L}^{-1}$ xylose concentration that is $12.6 \%$ xylose of the theoretical.

The arabinose reduced corn stover was subjected to a more severe hydrolysis (Figure 4). The ze- ro-time sample was withdrawn when the temperature reached $120{ }^{\circ} \mathrm{C}$, and during the heating period the hydrolysis already started resulting in significant initial total sugar yields. After 60 -minute reaction time in hydrolysis with $1.5 \%(\mathrm{w} / \mathrm{w})$ sulfuric acid, at $120{ }^{\circ} \mathrm{C}$, and with $7 \%(\mathrm{w} / \mathrm{w})$ dry matter, $16.4 \mathrm{~g} \mathrm{~L}^{-1}$ xylose was obtained on a pilot scale, which corresponds to $64.1 \%$ of theoretical maximum. Yields of glucose and arabinose were 7.2 \% and $45.1 \%$ of the theoretical, respectively.

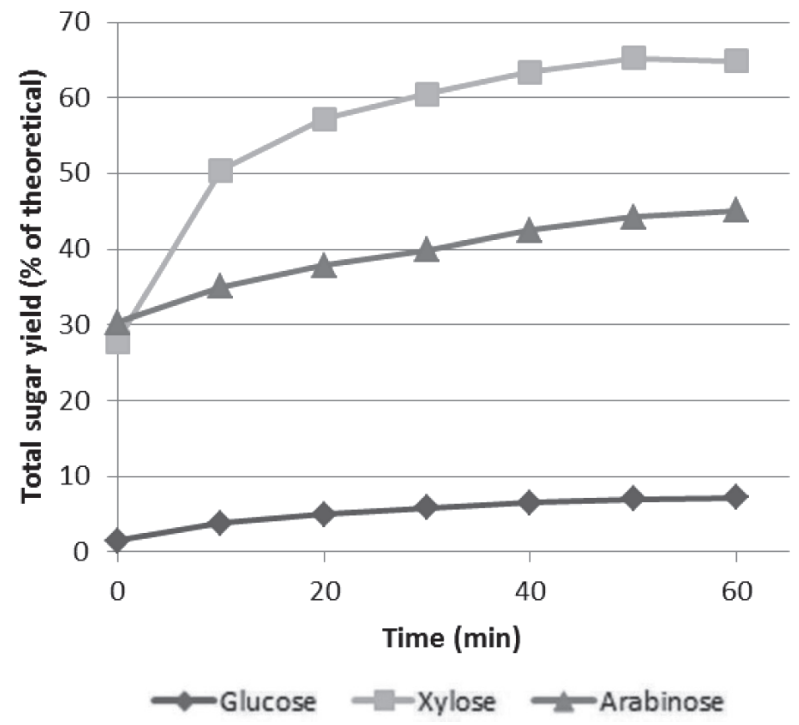

Fig. 4 - Hydrolysis with $1.5 \%(w / w)$ sulfuric acid, at $120{ }^{\circ} \mathrm{C}$ and with $7 \%(w / w)$ dry matter on arabinose reduced corn stover on a pilot scale. Arabinose removal was performed with $0.3 \%(w / w)$ sulfuric acid, at $90{ }^{\circ} \mathrm{C}$, 4-hour reaction time and with $10 \%(w / w)$ dry matter. 
Table 6 -Model parameters for the hydrolysis with $1.5 \%$ (w/w) sulfuric acid, at $120{ }^{\circ} \mathrm{C}$ and with $7 \%(w / w)$ dry matter on arabinose reduced corn stover on a pilot scale

\begin{tabular}{l|cccc}
\hline \multicolumn{1}{c|}{ Component } & Glucose & Xylose & Arabinose \\
\hline$k$, first-order $\left(\mathrm{min}^{-1}\right)$ & $1.4 \cdot 10^{-3}$ & $2.6 \cdot 10^{-2}$ & $7.3 \cdot 10^{-3}$ \\
$R^{2}$ & 0.90 & 0.88 & 0.98 \\
$k$, first-order, biphasic $\left(\mathrm{min}^{-1}\right)^{*}$ & $5.2 \cdot 10^{-2}$ & $8.5 \cdot 10^{-2}$ & - \\
$R^{2}$ & 0.99 & 0.99 & - \\
\hline
\end{tabular}

*Easy-to-hydrolyze fractions $(0.072$ and 0.649 for glucose and xylose, respectively) were assumed to be equal to the yields obtained at the end of the hydrolysis reaction.

Pilot scale experiment on arabinose reduced corn stover resulted in 0.74 selectivity at 60 -minute reaction time. Nearly the same $(S=0.72)$ selectivity was obtained in a one-step hydrolysis, at $120^{\circ} \mathrm{C}$, 60-minute reaction time, $5 \%(\mathrm{w} / \mathrm{w})$ dry matter with $2 \%(\mathrm{w} / \mathrm{w})$ sulfuric acid. Pilot scale experiment highlighted that a two-step hydrolysis (arabinose removing pre-hydrolysis and consequent xylose hydrolysis) did not result in significantly higher selectivity, however, the xylose yield was lower. Xylose hydrolysis in one-step required $20 \mathrm{~g}$ sulfuric acid per $100 \mathrm{~g}$ dry matter, while in the case of two-step hydrolysis, $21.2 \mathrm{~g}$ acid was used per $100 \mathrm{~g}$ dry matter. Based on these results, one-step hydrolysis can be more economical.

The arabinose formation showed first-order kinetics in the case of the hydrolysis of arabinose reduced corn stover (Table 6), and a high level of accuracy $\left(R^{2}\right)$ was obtained. However, the formation of glucose and xylose could be described accurately by the biphasic model; in the case of the first-order model, poor fits were observed, although the $R^{2}$ values do not reflect this.

\section{Conclusions}

Corn stover hydrolysis with sulfuric or hydrochloric acid gives high xylose yields. Although hydrochloric acid resulted in the highest, $88.8 \%$ xylose yield under the condition of $2 \%(\mathrm{w} / \mathrm{w})$ acid concentration, 40 -minute reaction time, $10 \%(\mathrm{w} / \mathrm{w})$ dry matter, at $120^{\circ} \mathrm{C}$, sulfuric acid was chosen for scaling up corn stover hydrolysis, since hydrochloric acid degrades xylose at reaction times longer than 40 minutes. Sulfuric acid hydrolysis with $7 \%$ $(\mathrm{w} / \mathrm{w})$ dry matter mainly results in low sugar concentrations, around $15 \mathrm{~g} \mathrm{~L}^{-1}$ xylose. The concentration of the hydrolyzate can be carried out with hydrolyzate recycling, since it has been proven in this study that recycling does not decrease the xylose yield. Hence, a three-step hydrolysis performed with recycled hydrolyzate can increase xylose concentration three times. Corn stover pre-hydrolysis with dilute sulfuric acid $\left(0.3 \%\right.$, w/w) at $90{ }^{\circ} \mathrm{C}$, 4-hour reaction time resulted in relatively high arabinose yield, $26.0 \%$ of theoretical, in the hydrolyzate while keeping the bulk of the xylose in the solid fraction. Sulfuric acid hydrolysis with mild conditions (acid concentration lower than $0.3 \%$, $\mathrm{w} / \mathrm{w}$ ) is suitable to produce arabinose reduced corn stover. Pilot scale experiment proved that arabinose reduced corn stover hydrolysis results in neither higher selectivity nor higher xylose yield. As in the two-step hydrolysis, nearly the same amount of sulfuric acid was applied per $100 \mathrm{~g}$ dry matter, it can be concluded that one-step acid hydrolysis can be the more economical option. The kinetic modelling of pre-hydrolysis and xylose hydrolysis based on the total sugar concentration revealed that the arabinose formation could be described by pseudo first-order kinetics, however, in the case of glucose the biphasic model performed well. The xylose formation in the hydrolysis of arabinose reduced corn stover could also be described accurately by the biphasic model, however, when soaking was applied prior to the pre-hydrolysis, the first-order kinetics gave good fit in the pre-hydrolysis.

\section{ACKNOWLEDGEMENTS}

The authors gratefully acknowledge the Project OTKA PD-108389 and OTKA PD-121024 of the Hungarian National, Research, Development and Innovation Office (NKFIH) and the New Hungary Development Plan (Project ID: TAMOP-4.2.1/B-09/1/KMR-2010-0002) for their financial support.

\section{References}

1. Avci, A., Saha, B. C., Dien, B. S., Kennedy, G. J., Cotta, M., Response surface optimization of corn stover pretreatment using dilute phosphoric acid for enzymatic hydrolysis and ethanol production, Bioresour. Technol. 130 (2013) 603. doi: https://doi.org/10.1016/j.biortech.2012.12.104

2. Menon, $V$., Rao, M., Trends in bioconversion of lignocellulose: Biofuels, platform chemicals \& biorefinery concept, Prog. Energy Combust. Sci. 38 (2012) 522. doi: https://doi.org/10.1016/j.pecs.2012.02.002

3. Hendriks, A., Zeeman, G., Pretreatments to enhance the digestibility of lignocellulosic biomass, Bioresour. Technol. 100 (2009) 10. doi: https://doi.org/10.1016/j.biortech.2008.05.027

4. Duguid, K. B., Montross, M. D., Radtke, C. W., Crofcheck, C. L., Wendt, L. M., Shearer, S., Effect of anatomical fractionation on the enzymatic hydrolysis of acid and alkaline pretreated corn stover, Bioresour. Technol. 100 (2009) 5189.

doi: https://doi.org/10.1016/j.biortech.2009.03.082

5. Weiss, N. D., Farmer, J. D., Schell, D. J., Impact of corn stover composition on hemicellulose conversion during dilute acid pretreatment and enzymatic cellulose digestibility of the pretreated solids, Bioresour. Technol. 101 (2010) 674. doi: https://doi.org/10.1016/j.biortech.2009.08.082 
6. Mosier, N., Hendrickson, R., Ho, N., Sedlak, M., Ladisch, $M$. R., Optimization of $\mathrm{pH}$ controlled liquid hot water pretreatment of corn stover, Bioresour. Technol. 96 (2005) 1986. doi: https://doi.org/10.1016/j.biortech.2005.01.013

7. Carvalheiro, F., Duarte, L. C., Gírio, F. M., Hemicellulose biorefineries: A review on biomass pretreatments, J. Sci. Ind. Res. (India) 67 (2008) 849.

8. Jacobsen, S. E., Wyman, C. E., Cellulose and hemicellulose hydrolysis models for application to current and novel pretreatment processes, Appl. Biochem. Biotechnol. 84-86 (2000) 81 .

doi: https://doi.org/10.1385/ABAB:84-86:1-9:81

9. Kapu, N. S., L., Tranjano, H., Review of hemicellulose hydrolysis in softwoods and bamboo, Biofuels, Bioprod. Biorefining 8 (2014) 857. doi: https://doi.org/10.1002/bbb.1517

10. Jennings, E. W., Schell, D. J., Conditioning of dilute-acid pretreated corn stover hydrolysate liquors by treatment with lime or ammonium hydroxide to improve conversion of sugars to ethanol, Bioresour. Technol. 102 (2011) 1240. doi: https://doi.org/10.1016/j.biortech.2010.08.024

11. Lee, J. Y., Ryu, H. J., Oh, K. K., Acid-catalyzed hydrothermal severity on the fractionation of agricultural residues for xylose-rich hydrolyzates, Bioresour. Technol. 132 (2013) 84. doi: https://doi.org/10.1016/j.biortech.2013.01.019

12. Sarkar, N., Ghosh, S. K., Bannerjee, S., Aikat, K., Bioethanol production from agricultural wastes: An overview, Renew. Energy 37 (2012) 19. doi: https://doi.org/10.1016/j.renene.2011.06.045

13. Zhang, J., Wang, X., Chu, D., He, Y., Bao, J., Dry pretreatment of lignocellulose with extremely low steam and water usage for bioethanol production, Bioresour. Technol. 102 (2011) 4480 doi: https://doi.org/10.1016/j.biortech.2011.01.005

14. Öhgren, K., Bura, R., Saddler, J., Zacchi, G., Effect of hemicellulose and lignin removal on enzymatic hydrolysis of steam pretreated corn stover, Bioresour. Technol. 98 (2007) 2503. doi: https://doi.org/10.1016/j.biortech.2006.09.003

15. Li, Z., Zhai, H., Zhang, Y., Yu, L., Cell morphology and chemical characteristics of corn stover fractions, Ind. Crops Prod. 37 (2012) 130. doi: https://doi.org/10.1016/j.indcrop.2011.11.025

16. Gao, P., Fan, D., Luo, Y., Ma, X., Ma, P., Hui, J., Efficient and comprehensive utilization of hemicellulose in the corn stover, Chinese J. Chem. Eng. 17 (2009) 350. doi: https://doi.org/10.1016/S1004-9541(08)60215-3

17. Lloyd, T., Wyman, C. E., Combined sugar yields for dilute sulfuric acid pretreatment of corn stover followed by enzymatic hydrolysis of the remaining solids, Bioresour. Technol. 96 (2005) 1967. doi: https://doi.org/10.1016/j.biortech.2005.01.011

18. Tucker, M. P., Kim, K. H., Newman, M. M., Nguyen, Q., Effects of temperature and moisture on dilute-acid steam explosion pretreatment of corn stover and cellulase enzyme digestibility, Appl. Biochem. Biotechnol. 105-108 (2003) 165. doi: https://doi.org/10.1385/ABAB:105:1-3:165

19. Zu, S., Li, W. Z., Zhang, M., Li, Z., Wang, Z., Jameel, H., Chang, H. M., Pretreatment of corn stover for sugar production using dilute hydrochloric acid followed by lime, Bioresour. Technol. 152 (2014) 364. doi: https://doi.org/10.1016/j.biortech.2013.11.034

20. Aguedo, M., Vanderghem, C., Goffin, D., Richel, A., Paquot, $M$., Fast and high yield recovery of arabinose from destarched wheat bran, Ind. Crops Prod. 43 (2013) 318. doi: https://doi.org/10.1016/j.indcrop.2012.07.029
21. Fehér, C., Gazsó, Z., Tatijarern, P., Molnár, M., Barta, Z., Réczey, K., Investigation of selective arabinose release from corn fibre by acid hydrolysis under mild conditions, J. Chem. Technol. Biotechnol. 90 (2015) 896. doi: https://doi.org/10.1002/jctb.4395

22. Lavarack, B. P., Griffin, G. J., Rodman, D., The acid hydrolysis of sugarcane bagasse hemicellulose to produce xylose, arabinose, glucose and other products, Biomass and Bioenergy 23 (2002) 367. doi: https://doi.org/10.1016/S0961-9534(02)00066-1

23. Jin, Q., Zhang, H., Yan, L., Qu, L., Huang, H., Kinetic characterization for hemicellulose hydrolysis of corn stover in a dilute acid cycle spray flow-through reactor at moderate conditions, Biomass and Bioenergy 35 (2011) 4158. doi: https://doi.org/10.1016/j.biombioe.2011.06.050

24. Gonzalez, G., Caminal, G., Hemicellulose at moderate temperature: A simplified kinetic model, Biotech. and Bioeng. 28 (1986) 288.

25. Esteghlalian, A., Hashimoto, A. G., Fenske, J. J., Penner, $M$. H., Modeling and optimization of the dilute-sulfuric-acid pretreatment of corn stover, poplar and switch grass, Bioresour. Technol. 59 (1997) 129. doi: https://doi.org/10.1016/S0960-8524(97)81606-9

26. Lenihan, P., Orozco, A., O’Neill, E., Ahmad, M. N. M., Rooney, D. W., Walker, G. M., Dilute acid hydrolysis of lignocellulosic biomass, Chem. Eng. J. 156 (2010) 395. doi: https://doi.org/10.1016/j.cej.2009.10.061

27. Liu, X., Lu, M., Ai, N., Yu, F., Ji, J., Kinetic model analysis of dilute sulfuric acid-catalyzed hemicellulose hydrolysis in sweet sorghum bagasse for xylose production, Ind. Crops Prod. 38 (2012) 81 doi: https://doi.org/10.1016/j.indcrop.2012.01.013

28. Yat, S. C., Berger, A., Shonnard, D. R., Kinetic characterization for dilute sulfuric acid hydrolysis of timber varieties and switchgrass, Bioresour. Technol. 99 (2008) 3855. doi: https://doi.org/10.1016/j.biortech.2007.06.046

29. Sluiter, A., Hames, B., Ruiz, R. O., Scarlata, C., Sluiter, J., Templeton, D., Determination of ash in biomass, Biomass Anal. Technol. Team Lab. Anal. Proced. (2004)

30. Sluiter, A., Hames, B., Ruiz, R., Scarlata, C., Sluiter, J., Templeton, D., Determination of structural carbohydrates and lignin in biomass, Lab. Anal. Proceed. (2011)

31. Templeton, D. W., Sluiter, A. D., Hayward, T. K., Hames, B. R., Thomas, S. R., Assessing corn stover composition and sources of variability via NIRS, Cellulose 16 (2009) 621. doi: https://doi.org/10.1007/s10570-009-9325-x

32. Qin, L., Liu, Z. H., Li, B. Z., Dale, B. E., Yuan, Y. J., Mass balance and transformation of corn stover by pretreatment with different dilute organic acids, Bioresour. Technol. 112 (2012) 319. doi: https://doi.org/10.1016/j.biortech.2012.02.134

33. Lu, X., Zhang, Y., Liang, Y., Yang, J., Zhang, S., Suzuki, E., Kinetic studies of hemicellulose hydrolysis of corn stover at atmospheric pressure, Korean J. Chem. Eng. 25 (2008) 302. doi: https://doi.org/10.1007/s11814-008-0053-y

34. Dominguez, J. M., Cao, N., Gong, C. S., Tsao, G. T., Dilute acid hemicellulose hydrolysates from corn cobs for xylitol production by yeast, Bioresour. Technol. 61 (1997) 85. doi: https://doi.org/10.1016/S0960-8524(97)84703-7

35. Shibanuma, K., Takamine, K., Maseda, S., Osaki, S., Abet, J., Hizukuri, S., Partial acid hydrolysis of corn fiber for the production of L-arabinose, J. Appl. Glycosci. 46 (1999) 249. doi: https://doi.org/10.5458/jag.46.249 